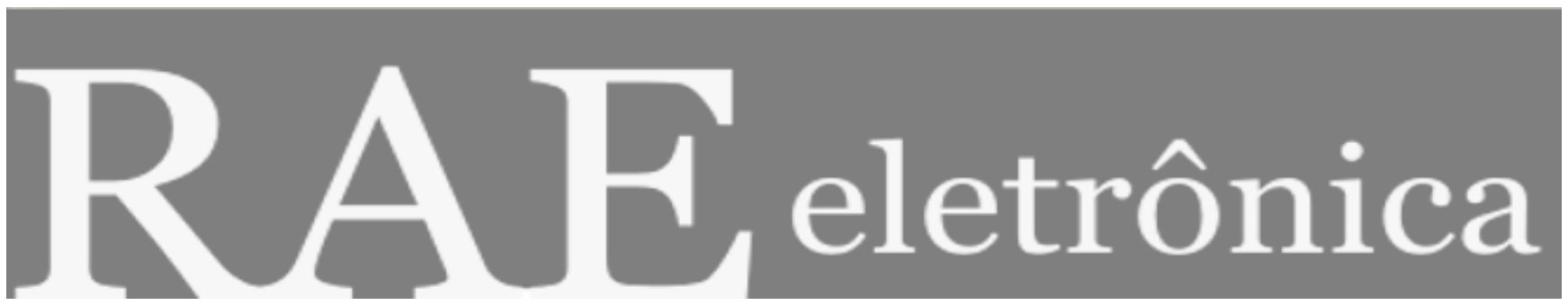

\title{
EXPLORAÇÃO, COLONIALISMO E LUTA PELA DEMOCRACIA NA AMÉRICA LATINA
}

Por:

\section{Maurilio Galdino Emannuel Rauffelt}

RAE-eletrônica, v. 2, n. 2, jul-dez/2003.

http://www.rae.com.br/eletronica/index.cfm?FuseAction=Artigo\&ID=2044\&Secao=RESENHAS\&Vol ume $=2 \&$ Numero $=2 \&$ Ano $=2003$

CCopyright, 2002, RAE-eletrônica. Todos os direitos, inclusive de tradução, são reservados. É permitido citar parte de artigos sem autorização prévia desde que seja identificada a fonte. A reprodução total de artigos é proibida. Os artigos só devem ser usados para uso pessoal e nãocomercial. Em caso de dúvidas, consulte a redação: redacao@,rae.com.br.

A RAE-eletrônica é a revista on-line da FGV-EAESP, totalmente aberta e criada com o objetivo de agilizar a veiculação de trabalhos inéditos. Lançada em janeiro de 2002, com perfil acadêmico, é dedicada a professores, pesquisadores e estudantes. Para mais informações consulte o site www.rae.com.br/eletronica.

RAE-eletrônica

ISSN 1676-5648

(C)2002 Editora: Fundação Getulio Vargas - Escola de Administração de Empresas de São Paulo.

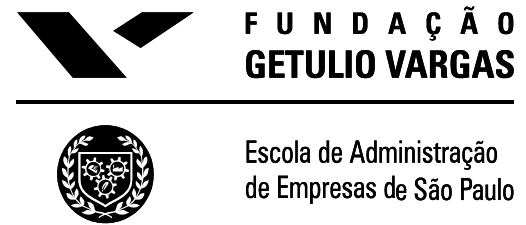


Por:

\title{
Maurilio Galdino
}

Doutorando em Ciências Políticas na Universidade de Montreal.

E-mail: $\underline{\text { mlgaldino@aol.com }}$

\section{Emannuel Rauffelt}

Professor de Administração e Meio-Ambiemte na HEC-Universidade de Montreal.

E-mail: emmanuel.raufflet@hec.ca

\author{
Exploração, Colonialismo e Luta Pela Democracia na América Latina \\ De Pablo González Casanova \\ Petrópolis: Vozes, 2002, 320 p.
}

\section{Introdução}

Havia um clima de frustração durante o Congresso da Associação Latinamericana de Sociologia, na Cidade do México, em 1996. Os Zapatistas estavam no que Sidney Tarrow chama de fase optimal do movimento, mas os 300 mil estudantes mexicanos da UNAM eram ameaçados pela privatização, militantes do MST eram massacrados em Eldorado dos Carajas e Emir Sader nos falava com tristeza do métier de dois ex-sociólogos, então neoliberais e presidentes da república no Brasil e na Venezuela. Pablo Gonzáles Casanova, contudo, estava otimista e feliz por presenciar a crise do modelo neoliberal e a volta da esquerda e da sociologia militante na América Latina.

Talvez a melhor imagem de Casanova seja a do pensador militante, como foram os intelectuais até 1920 e que Michael Lowy chama de românticos (A Guerra dos Deuses, Vozes). Pensar a sociedade para transformá-la, não para corrigi-la... Essa espécie de pensador foi quase extinta pela burocracia e pelo metodismo científico no século XX e renasce hoje graças ao testemunho e carisma dos poucos que, como Casanova, insistiram na ética e na teoria da praxis. Essa distinção inicial é fundamental para compreender a antologia de Casanova.

Casanova é um marxista que promove a democracia como estratégia principal da transformação social. Esta estratégia foi adotada pelos "novos movimentos sociais" à partir dos anos 60 e reafirmada pelos "socialistas" depois da Queda do Muro de Berlim, em 1989. Podemos encontrar os principais argumentos dessa estratégia no clássico livro de Ellen Wood, Democracy against Capitalism (Verso, 1996). Indentificado como um marxista da Escola Crítica (p.12-13), Casanova está muito próximo da Nova Esquerda (New Left) ou Escola Política do marxismo anglo saxão (norteamericano). ${ }^{1} \mathrm{O}$ rótulo de marxista crítico, contudo, não ajuda, pois o marxismo é secundário em relação à sua preocupação e compromisso com o método científico ou "ciência" das ciências sociais. Como diz Rosenmann na Introdução, seus postulados buscam um debate teórico e sociológico, mas democrático e crítico (p.9).

Segundo Rosenmann, essa antologia de Casanova contém suas obras mais representativas e que mostram a evolução de seu pensamento. O títuto sintetiza os temas estratégicos, o percurso e o contexto onde o pensamento de Casanova se forjou. Mas a lógica neles contida é perene: a análise epistemológica. Tradução do livro La Democracia en México (1993), essa antologia em português tem 320 páginas e traz dois capítulos inéditos (4 e 11) e três capítulos recentes (capítulo 8, 12 e 13),

\footnotetext{
${ }^{1}$ A escola política marxista se baseia no Capital III e 18 Brumário, de Karl Marx, onde o modo de produção corresponde à forma de apropriação da mais-valia. Essa apropriação é geralmente política ou "negociada" (Cf. The Brener Debate, Verso).
} 
publicados entre 1992 e 2001. A antologia de Casanova se divide em três partes: a primeira sobre a exploração e o capitalismo global, a segunda sobre a luta pela democracia e a terceira sobre a contribuição do socialismo para a teoria política, as ciências sociais e a democracia.

\section{Epistemologia}

Casanova questiona duramente a antropologia clássica porque, segundo ele, apesar de nos ajudar a conhecer a realidade do excluído e explorado com um senso humanista, essa antropologia nunca foi anticolonialista, "nem na época revolucionária". Segundo ele, uma ciência da metrópole não consegue pensar à partir da colônia, seus dados são descritivos, não uma denúncia (p.79-80). O capítulo primeiro é um bom exemplo de seu método. A descrição quantitativa do México, no olhar de Casanova, nos revela um Outro México, um México profundo por detrás dos números. Mas o autor não é pretensioso e sabe que o o acúmulo de conhecimentos e de estudos nessa perspectiva (p.135) poderá nos ajudar, por exemplo, a conhecer melhor o Outro México (p.80).

Casanova é antes de tudo um sociólogo: organizar a sociologia enquanto ciência distinta da filosofia e da política. A sociologia européia teve uma orígem quantitativa, na estatística alemã do século XVIII e XIX. Durkeim dá à estatísca o instrumento qualitativo ou cultural - ainda que ligado a uma visão de extensão territorial e de sociedade complexa. Assim, para Casanova existem duas formas de fazer sociologia: uma quantitativa e outra qualitativa. Nesse ponto se dá uma primeira ruptura entre o seu pensamento e o marxismo. Segundo ele, não existe distinção entre a sociologia científica da marxista quando ambas querem "conhecer para controlar as variáveis do sistema, não para transformar o sistema". Casanova também se distingue do liberalismo-empírico (conservador ou marxista) nas categorias que utiliza. Nesse ponto se dá a segunda ruptura, entre o seu pensamento e a teoria da dependência que, para ele, se equivocou ao pensar a dependência em termos de desigualdade e não de exploração. Ou seja, enquanto mecanismos sistêmicos de reprodução interna do sistema (colonialismo interno) e de controle eficiente do protesto através do Estado (definição abaixo).

Casanova não tem medo de se expor, de denunciar que não é a frieza que permeia a ciência, mas a paixão e o pre-conceito. Mas ele "não se apaixona por suas idéias. Desenvolve-as e critica-as como parte indissociável do trabalho intelectual" (p.9). Uma primeira denúncia se refere ao modernismo liberal-empírico de um Friedman, que vê a economia como variável principal da modernidade. Boa parte da obra faz a crítica epistemológica sobre:

a) os valores e ideologia que o pesquisador leva para sua obra e as formas de evitar que isso esconda a realidade.

b) o problema da transposição de categorias de uma ciência (biologia, física, economia, etc.) ou de uma área de estudo para outra. Por exemplo, de categorias das relações internacionais, como colonialismo, para o estudo das relações intranacionais, como a exploração. O conceito de colonialismo dá conta de uma realidade internacional, mas restringe o colonialismo intranacional da sociedade plural (p.82).

c) os pré-conceitos contidos na filosofia do pesquisador, como desigualdade, que na visão liberal se opõe ao conceito de igualdade individual, não coletiva. Um outro pré-conceito sendo o de desenvolvimento, que na visão liberal carrega a tonalidade do conceito de processo, ou de evolução, de algo pior ou menos bom para algo melhor ou mais bom, etc.

d) o problema dos modelos metafísicos - do idealismo burguês ou do determinismo marxista vulgar - que não consideram a realidade histórica e contraditória, a "liberdade e 
responsabilidade dos homens, não obstante a existência de determinismos econômicos e estruturais" (p.129). "Um típico erro metafísico, que a velha tradição da causa prima possui, presente em tudo, explicando tudo, sendo tudo" (p.134).

Casanova faz sociologia aplicada em torno do que chama sociologia da exploração (capítulo 3). Ele também vê a economia como base de análise, mas não de maneira mecânica. Para ele, a economiapolítica (a superestrutura) é a variável independente da modernidade e do desenvolvimento (a estrutura). Os indicadores que decorrem de suas categorias são coerentes... Por exemplo, o seu famoso conceito de "colonialismo interno" (capítulo 2) utiliza indicadores como a quantidade de sandálias ou sapatos usados pelos mexicanos, pela farinha de trigo ou de milho, pelo bilinguismo ou monolinguismo rural, pela integração ou exclusão no mercado do mexicano pobre, no campo e na cidade. Segundo Casanova, "um modelo de investigação integral e básica requer que se vá às fontes qualitativas da investigação, realizando na elaboração do próprio modelo o vai-vem dos termos qualitativos aos quantitativos e vice versa" (p.12).

Ironicamente, a sua categoria de "democracia do poder" segue uma lógica econômica: "é necessário que por trás do voto, e sob a representação, esteja representado o poder do povo... da participação do povo na propriedade e no consumo" (p.169). Para Casanova, por exemplo, "Estado é o poder de dispor da economia. Este poder pode se basear na persuasão, na coação ou na negociação, ou seja, na hegemonia ou na repressão" (p.173). Assim, Casanova identifica cinco indicadores para medir a democracia: "a repressão, a negociação, a representação, a participação e a mediação" (p.167). Essas variáveis diferem bastante das variavéis e do ideal-tipo "elitista" de O’Donnell, Schmitter and Whitehead. ${ }^{2}$

Casanova tem uma linguagem política e engajada que transforma a sua obra num manifesto. Isso facilita a leitura do texto para um público menos próximo do debate epistemológico e metodológico. ${ }^{3}$ Talvez as páginas 112-125 sejam as mais ásperas, mas pelo menos nós não precisamos estudar as obras que estão nas notas de rodapé. Assim, essa antologia de de Casanova é popular e eletrizante, próxima de um jovem Marx ou de um contemporâneo mexicano como José Porfírio Miranda (Marx y la Bíblia, Siglo XXI).

\section{Crítica}

O pensamento de Casanova é inovador, mas bipolar: duas ciências, dois métodos, dois povos, duas classes, nação versus império, enfim, dominantes e dominados... Essa escolha tem a força heurística da retórica, mas é questionada hoje como um dos impecilhos mais importantes para a transição democrática no campo ou para um "consenso democrático". ${ }^{4} \mathrm{O}$ maior problema de Casanova se encontra no eixo ideológico que marcou a sua geração: a luta de classes, os "inimigos" de classe. E

\footnotetext{
2. Segundo a teoria da transição democrática, os moderados devem se afastar dos militares duros e dos movimentos sociais radicais e achar um equilíbrio entre as forças domésticas (grupos sociais, intelectuais e partidos) e atores internacionais que possuem os meios para compensar os custos de reformas econômicas em tempo de crise. Infelizmente, na América Latia os duros não são excluídos desse modelo, só os radicais.

${ }^{3}$ Vejam, por exemplo, essa frase: "O descobrimento da relação humana da exploração pelo marxismo causa tal desagrado e incerteza no homem burguês... é algo como A Queda do Ego e é rejeitada pela consciência de um... proprietário, com toda sua cultura e tradição filosófica e científica" (p.132).

${ }^{4}$ O Consenso é outra estratégia que foi adotada pelos governos socialistas, como o de Erundina, de Lula e utilizado até mesmo na democracia interna do MST. Isso porque o voto é muito mecânico, disruptivo e causa de polarizações indesejadas ou "divisionistas" (Cf. Kowarick, L. and A. Singer, "The Workers' Party in São Paulo." In Social Struggles and the City, ed. L. Kowarick, New York, Monthly Review Press, 1994, pp.225-256).
} 
mesmo quando ele pensa em alianças, isso se apresenta numa linguagem da física, como correlação ou "reacomodação de forças... nacionais e de classe" (p.172).

Hoje a sociedade global nos força a pensar a estratégia com termos mais soft \& light, como "adversários de classe". O inimigo a gente destrói; o adversário a gente respeita dentro das regras do jogo; etc... Esses detalhes terminológicos facilitam, por exemplo, uma aliança mais larga entre as forças sociais dispersas e fragmentadas (Barbara Epstein). Isso não quer dizer que Casanova não esteja certo, somente que seu discurso é situado, histórico, e que o nosso discurso mudou para enfrentar uma outra situação histórica: a globalização.

Um outro limite é que sua análise da democracia não diz o como... A participação do povo no poder, ou seja, "na propriedade e no consumo", por exemplo, é conservadora e individualista e gerou o corporativismo sindical na política. Outro exemplo, qual é o lugar do movimento social na democracia do poder? O marxismo-leninismo, pelo menos, deixava claro que o movimento social seria a base de um partido socialista e que ele teria uma "autonomia organizacional" dentro do partido político, mas não uma autonomia estratégica (Ernest Mendel). Sabemos que os movimentos sociais viraram correias de transmissão no que ficou conhecido como centralismo democrático dos PCs, mas nas 320 páginas de Casanova temos somente postulados teóricos, não uma alternativa concreta à democracia representativa.

No geral, essa coletânea de Casanova mostra que não era só de Cardoso que se fazia sociologia na América Latina entre 1960 e 2000 . Muito parecido com um ensaio político, essa antologia está entre o que de melhor se produziu nessa época. Finalmente, a linguagem polêmica, poucas referências bibliográficas e a descrição de casos e métodos estranhos aos estudantes brasileiros contribui bastante para animar a discussões de casos importantes para as ciências sociais no Brasil. E isso acompanhado da vida de um gigante, que leva a análise e o compromisso com a transformação social até as últimas consequências - mesmo que limitado pela história e pela ciência de seu tempo. 